\title{
Evaluation of the i-STAT Point-of-Care Analyser
}

\author{
YeJin Oh, Sun Hoe Koo, \\ and Gye Cheol Kwon \\ Department of Laboratory \\ Medicine, Chungnam \\ National University \\ Hospital, Chungnam \\ National University School \\ of Medicine, Daejeon, Korea
}

Corresponding author:

Gye Cheol Kwon

Department of Laboratory

Medicine, Chungnam National

University Hospital, Chungnam

National University School of

Medicine, 282 Munhwa-ro, Jung-

gu, Daejeon 35015, Korea

Tel: $+82-42-280-7799$

Fax: +82-42-257-5365

E-mail: kckwon@cnu.ac.kr

pISSN: 2384-2458

eISSN: 2288-7261
Background: Point-of-care testing (POCT) is designed to be used near the site where the clinical care is being delivered. The demand for POCT in the medical field is expanding significantly, given that rapid results can eventually lead to early diagnosis and immediate clinical management of diseases. Therefore, the aim of this study was to evaluate the performance of the i-STAT POC analyser (Abbott Diagnostics, USA) for testing 8 chemical analytes (viz., sodium, potassium, chloride, total carbon dioxide, blood urea nitrogen, creatinine, glucose, and ionised calcium) and 2 hematological analytes (hematocrit [HCT], hemoglobin $[\mathrm{Hb}])$.

Methods: The precision and linearity of the 10 analytes were measured according to Clinical and Laboratory Standards Institute (CLSI) EP15-A3 and EP6-A guidelines. Comparisons with a central laboratory hematology analyser, Coulter LH 780 (Beckman Coulter Inc., USA), and a chemical analyser, UniCel DxC 880i (Beckman Coulter Inc.), were performed using 85 patient samples according to CLSI EP9-A3.

Results: The coefficient of variation values for the within-run precision and total precision at 3 levels of all analytes were within 5\%, except those for low level creatinine. In the aspect of linearity, the correlation coefficient values of all analytes were over 0.975 in the clinically important concentration range. A very high correlation was observed in glucose, blood urea nitrogen and creatinine $(R>0.975)$, high correlation was observed in sodium, potassium, Hct and $\mathrm{Hb}(R>0.9)$, and relatively good correlation was observed in chloride and total carbon dioxide $(R>0.7)$ compared to the central laboratory analysers.

Conclusions: i-STAT showed relatively high precision and linearity, and comparable data to that of routine hematology and chemistry analysers. This device was concluded to have potential for providing faster results and relatively acceptable values to clinicians in need of immediate results.

(J Lab Med Qual Assur 2016;38:225-233)

Key Words: Point-of-care systems, i-STAT, Evaluation studies

Received April 12, 2016, Revision received August 10, 2016, Accepted August 23, 2016

\section{서론}

현장검사(point of care testing)란 중앙검사실을 벗어나 진 료가 이루어지는 장소에서 시행되는 진단검사로 최근 그 수요 가 증가하고 있다[1]. 현장검사는 검체 채취 후 중앙검사실로 의 운송뿐만 아니라 원심분리 등과 같은 검체 전처리과정이 없 기 때문에 신속하게 결과 확인이 가능하고 이로 인해 좀 더 빠 르게 환자를 진단 및 치료할 수 있다[2]. 또한 채혈량을 줄임 으로써 환자들의 만족도 향상에 기여하며, 신속한 검사결과를 제시하여 많은 환자를 진료하여야 하는 임상의사들의 요구에 도 부합한다[3].

i-STAT (Abbott Diagnostics, Abbott Park, IL, USA)은
휴대 가능한 현장검사 장비로써 전기화학측정원리를 기반으 로 $95 \mu \mathrm{L}$ 의 전혈을 이용하여 120 초 안에 검사가 진행된다. 사 용되는 일회용 카트리지(cartridge) 종류에 따라 전해질, 동맥 혈가스, 심근표지자, 화학검사 및 혈색소 등 19 개의 항목을 분 석할 수 있다. 또한 이 장치는 카트리지 내에 보정물질을 포함 하여 검체 측정 전 자동 보정(self-calibrating)을 하는 시스템 이 포함되어 있고 간단한 조작으로도 다룰 수 있어 비숙련자의 경우에도 쉽게 이용할 수 있는 장점도 있다[4,5]. 여러 종류의 카트리지 중 $\mathrm{CHEM} 8+$ 는 전해질검사와 신기능검사, 혈당검 사 및 혈색소검사를 포함하고 있고 이는 대부분의 의료환경에 서 기본적인 환자의 상태를 알 수 있는 검사로 매우 중요하다 [6]. 
현재 몇몇 병원에서 i-STAT CHEM8+를 이용하여 현장검 사를 시행하고 있지만 결과값에 대한 정확도나 정밀도에 대한 국내정보는 아직 충분하지 않다. 이에 본 연구에서는 현장검사 장비인 i-STAT CHEM8+를 이용하여 혈액의 나트륨 $\left(\mathrm{Na}^{+}\right)$, 칼륨 $\left(\mathrm{K}^{+}\right)$, 염소 $\left(\mathrm{Cl}^{-}\right)$, 총 이산화탄소(total $\left.\mathrm{Co}_{2}, \mathrm{TCO}_{2}\right)$, 이온
화 칼슘(ionized calcium, $\mathrm{iCa}^{2+}$ ), 혈당(glucose), 혈액요소질 소(blood urea nitrogen, BUN), 크레아티닌(creatinine, $\mathrm{Cr}$ ), 헤마토크릿(hematocrit, Hct), 헤모글로빈(hemoglobin, $\mathrm{Hb}$ ) 농도를 측정하여 그 수행능을 평가하고자 하였다.

Table 1. Coefficient of variation values for the within-run precision and total precision of i-STAT CHEM8+

\begin{tabular}{|c|c|c|c|c|c|c|}
\hline \multirow{2}{*}{ Analytes (unit) } & \multirow{2}{*}{ Sample } & \multirow{2}{*}{ Mean } & \multicolumn{2}{|c|}{ Within-run precision } & \multicolumn{2}{|c|}{ Total precision } \\
\hline & & & SD & CV (\%) & SD & CV (\%) \\
\hline \multirow[t]{3}{*}{$\mathrm{Na}^{+}(\mathrm{mmol} / \mathrm{L})$} & Low & 121.9 & 0.6 & 0.5 & 0.8 & 0.7 \\
\hline & Middle & 131.2 & 0.6 & 0.5 & 0.6 & 0.5 \\
\hline & High & 158.5 & 1.1 & 0.7 & 1.2 & 0.8 \\
\hline \multirow[t]{3}{*}{$\mathrm{K}^{+}(\mathrm{mmol} / \mathrm{L})$} & Low & 2.84 & 0.06 & 2.1 & 0.06 & 2.2 \\
\hline & Middle & 3.79 & 0.03 & 0.8 & 0.03 & 0.8 \\
\hline & High & 6.11 & 0.04 & 0.6 & 0.06 & 1.0 \\
\hline \multirow[t]{3}{*}{$\mathrm{Cl}^{-}(\mathrm{mmol} / \mathrm{L})$} & Low & 73.1 & 0.8 & 1.1 & 1.1 & 1.6 \\
\hline & Middle & 91.7 & 1.0 & 1.1 & 1.1 & 1.2 \\
\hline & High & 113.0 & 1.8 & 1.6 & 1.8 & 1.6 \\
\hline \multirow[t]{3}{*}{ Ionised $\mathrm{Ca}(\mathrm{mmol} / \mathrm{L})$} & Low & 0.872 & 0.011 & 0.8 & 0.007 & 1.2 \\
\hline & Middle & 1.334 & 0.017 & 1.3 & 0.022 & 1.6 \\
\hline & High & 1.651 & 0.027 & 1.7 & 0.027 & 1.7 \\
\hline \multirow[t]{3}{*}{ Total $\mathrm{CO}_{2}(\mathrm{mg} / \mathrm{dL})$} & Low & 18.9 & 0.5 & 2.9 & 0.6 & 2.9 \\
\hline & Middle & 25.4 & 0.7 & 2.6 & 0.7 & 2.8 \\
\hline & High & 28.6 & 0.9 & 3.3 & 0.9 & 3.3 \\
\hline \multirow[t]{3}{*}{ Glucose (mg/dL) } & Low & 38.6 & 0.3 & 0.8 & 0.5 & 1.4 \\
\hline & Middle & 124.7 & 0.6 & 0.5 & 0.9 & 0.8 \\
\hline & High & 270.8 & 1.0 & 0.4 & 1.3 & 0.5 \\
\hline \multirow[t]{3}{*}{ Blood urea nitrogen $(\mathrm{mg} / \mathrm{dL})$} & Low & 6.0 & 0 & 0 & 0 & 0 \\
\hline & Middle & 11.0 & 0 & 0 & 0 & 0 \\
\hline & High & 55.7 & 0.6 & 1.1 & 0.8 & 1.4 \\
\hline \multirow[t]{3}{*}{ Creatinine $(\mathrm{mg} / \mathrm{dL})$} & Low & 0.31 & 0.02 & 7.3 & 0.02 & 7.3 \\
\hline & Middle & 1.11 & 0.02 & 2.0 & 0.02 & 2.0 \\
\hline & High & 3.97 & 0.10 & 2.5 & 0.10 & 2.6 \\
\hline \multirow[t]{3}{*}{ Hematocrit (\%PCV) } & Low & 16.1 & 0.3 & 2.0 & 0.3 & 2.0 \\
\hline & Middle & 31.7 & 0.4 & 1.4 & 0.7 & 2.2 \\
\hline & High & 52.0 & 0.3 & 0.6 & 0.3 & 0.6 \\
\hline \multirow[t]{3}{*}{ Hemoglobin (g/dL) } & Low & 5.44 & 0.13 & 2.3 & 0.13 & 2.3 \\
\hline & Middle & 10.77 & 0.25 & 2.3 & 0.18 & 1.7 \\
\hline & High & 17.70 & 0.12 & 0.7 & 0.11 & 0.6 \\
\hline
\end{tabular}




\section{재료 및 방법}

본 연구는 충남대학교병원의 임상연구심의위원회(institutional review board) 심의를 얻어 진행되었다(CNUH IRB 2014-09-006).

\section{1. 정밀도}

정밀도 평가는 Clinical and Laboratory Standards Institute (CLSI) EP15-A3 [7]에 따라 5일에 걸쳐 오전과 오 후 2 차례씩 제조사에서 제공하는 저농도, 중간 농도, 그리고 고농도의 정도관리물질(Abbott Point of Care Inc., Abbott Park, IL, USA)을 이용하여 두 차례 반복 측정하였다. 각 농 도에 대한 정도관리물질의 결과값의 평균 및 검사차례 내 표준 편차와 변이계수, 총 표준편차와 총 변이계수를 계산하였다.

\section{2. 직선성}

직선성 평가는 CLSI EP6-A [8]에 따라 제조사에서 제공 하는 5 가지 농도의 정도관리물질인 i-STAT Co. Calibration Verification Set level 1, level 2, level 3, level 4, level 5 (Abbott Point of Care Inc.)를 이용하여 각각 4회씩 반복하여 측정하였다.

\section{3. 상관성}

상관성 평가는 CSLI EP9-A3 [9]에 따라 분석하였다. 충남 대학교병원 응급실에 내원한 환자들 중 85명을 대상으로 정 맥을 채혈한 즉시 소량의 검체는 전혈상태로 i-STAT 장비에 서 $\mathrm{CHEM} 8+$ 에 해당하는 10 가지 항목을 측정하였고 나머 지 혈액은 K3 EDTA 채혈관(Greiner Bio-One, Solingen, Germany)과 혈청분리관(Greiner Bio-One)에 채취하여 중
앙검사실 장비인 Coulter LH 780 (Beckman Coulter Inc., Brea, CA, USA)와 Beckman Unicel DxC 880i (Beckman Coulter Inc.)로 검사하여 측정한 결과값을 서로 비교 · 분석하 였다.

\section{4. 통계처리}

통계분석은 Analyse-it ver. 3.76 (Analyse-It Software Ltd., Leeds, England)을 이용하였다. 정밀도 평가를 위하 여 평균 및 검사차례 내 표준편차와 변이계수, 총 표준편차와 총 변이계수를 계산하였다. 직선성은 선형회귀분석을 통하여 회귀방정식과 결정계수를 구하였다. 상관성의 평가에는 중앙 검사실 장비인 Coulter LH 780 (Beckman Coulter Inc.)과 Beckman Unicel DxC 880i (Beckman Coulter Inc.)를 기준 으로 하여 i-STAT 결과에 대하여 Deming 회귀분석을 시행하 였고 회귀선의 기울기, 절편, 상관계수를 구하였다. 또한 임상 적 중요 농도에서의 i-STAT 측정 예측치를 계산하여 평가하 였고[10], Bland-Altman 분석을 시행하여 바이어스를 측정 하였다.

\section{결과}

\section{1. 정밀도}

제조사에서 제공하는 저농도, 중간농도, 그리고 고농도의 정 도관리물질을 각각 사용하여 $\mathrm{CHEM} 8+$ 에 해당하는 항목인 $\mathrm{Na}^{+}, \mathrm{K}^{+}, \mathrm{Cl}^{-}, \mathrm{TCO}_{2}, \mathrm{iCa}^{2+}$, glucose, $\mathrm{BUN}, \mathrm{Cr}, \mathrm{Hct}, \mathrm{Hb}$ 에 대한 결과값의 평균 및 검사차례 내 표준편차와 변이계수, 총 표준편차와 변이계수를 Table 1 에 정리하였다. 측정한 10 가지 항목 중 저농도 $\mathrm{Cr}$ 만 제외하고 저농도, 중간농도와 고농도의 정도관리물질 모두 검사차례 내 및 총 변이계수가 $5 \%$ 미만이

Table 2. The linearity of data measured by i-STAT CHEM8+

\begin{tabular}{lcccc}
\hline \multicolumn{1}{c}{ Analytes (unit) } & Range & Slope & Intercept & $R^{2}$ \\
\hline $\mathrm{Na}^{+}(\mathrm{mmol} / \mathrm{L})$ & $99.8-179.0$ & 1.00 & 0.42 & 0.9998 \\
$\mathrm{~K}^{+}(\mathrm{mmol} / \mathrm{L})$ & $2.11-7.77$ & 1.00 & -0.03 & 1.0000 \\
$\mathrm{Cl}^{-}(\mathrm{mmol} / \mathrm{L})$ & $72.5-122.0$ & 1.00 & -0.73 & 0.9997 \\
Ionised Ca (mmol/L) & $0.25-2.35$ & 1.06 & -0.02 & 0.9998 \\
Total CO $(\mathrm{mg} / \mathrm{dL})$ & $12.0-39.4$ & 0.89 & 2.30 & 0.9823 \\
Glucose $(\mathrm{mg} / \mathrm{dL})$ & $26.6-634.1$ & 1.02 & -0.37 & 1.0000 \\
Blood urea nitrogen $(\mathrm{mg} / \mathrm{dL})$ & $4.7-114.7$ & 1.02 & 0.27 & 0.9995 \\
Creatinine (mg/dL) & $0.49-14.86$ & 1.12 & -0.28 & 0.9994 \\
Hematocrit (\%PCV) & $16.0-53.5$ & 1.03 & -0.29 & 0.9875 \\
Hemoglobin $(\mathrm{g} / \mathrm{dL})$ & $5.4-18.2$ & 1.01 & 0.33 \\
\hline
\end{tabular}


었다. 저농도 $\mathrm{Cr}$ 의 검사차례 내 및 총 변이계수는 $7.3 \%$ 를 보 였다.

\section{2. 직선성}

제조사에서 제공하는 5 가지 농도의 정도관리물질을 각각 사 용하여 $\mathrm{CHEM} 8+$ 에 해당하는 항목인 $\mathrm{Na}^{+}, \mathrm{K}^{+}, \mathrm{Cl}^{-}, \mathrm{TCO}_{2}$, $\mathrm{iCa}^{2+}$, glucose, BUN, Cr, Hct, $\mathrm{Hb}$ 에 대한 직선성, 기울기, 절편 및 결정계수를 Table 2에 정리하였다. 결정계수는 평가 항목 모두 0.975 이상이었다(Fig. 1). 직선성을 평가하는데 사 용한 5 가지 농도의 정도관리물질은 임상 검체에서 일반적으로 측정되는 값을 모두 포함하였다.

\section{3. 상관성}

임상 검체를 i-STAT CHEM8+와 Coulter LH 780 (Beckman Coulter Inc.) 및 Beckman Unicel DxC 880i (Beckman Coulter Inc.)에서 측정한 결과값과 각각 비교 · 분석하였다. Glucose, BUN, Cr은 상관계수가 각각 0.99, $0.98,0.99$ 로 0.975 이상이었고 $\mathrm{Na}^{+}, \mathrm{K}^{+}, \mathrm{Hct}, \mathrm{Hb}$ 에서는 각

A

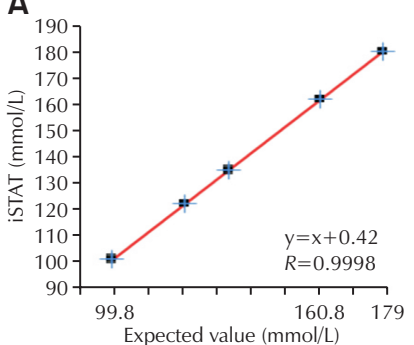

E

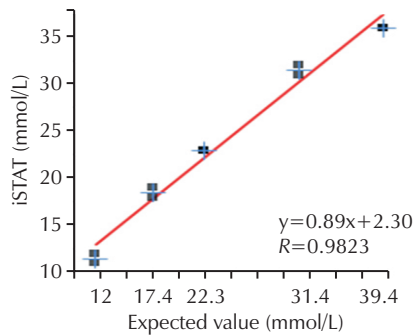

I

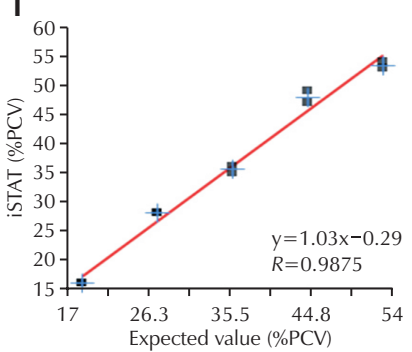

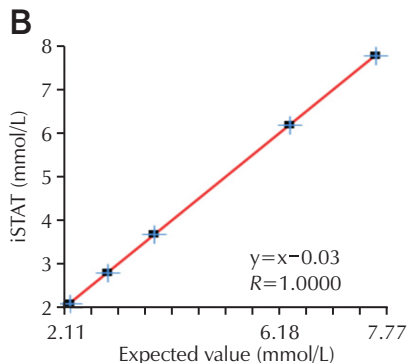

$\mathbf{F}$

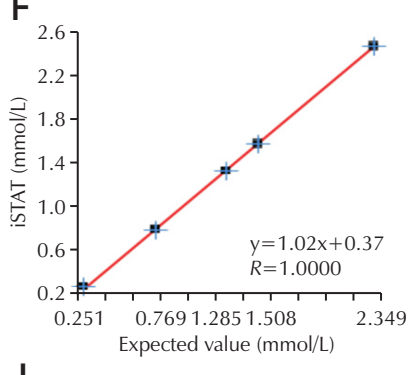

J

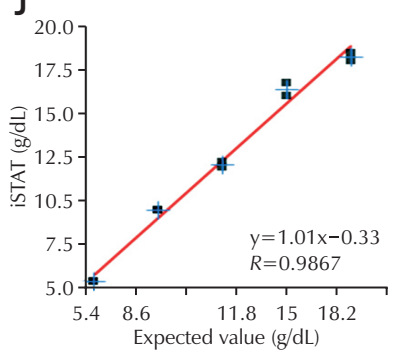

각 $0.93,0.95,0.92,0.94$ 로 0.9 이상이었으며, $\mathrm{Cl}^{\prime}$ 과 $\mathrm{TCO}_{2}$ 의 상관계수는 0.90 과 0.74 로 0.7 이상이었다 임상적 중요 농도에 서의 i-STAT 측정 예측치를 계산하여 얻은 결과치는 Table 3 과 같았다(Fig. 2). 또한 Clinical Laboratory Improvement Amendments (CLIA)에서 제시하는 허용오차범위를 만족 하지 못하는 검체의 비율은 $\mathrm{K}^{+}, \mathrm{Cl}^{-}$, glucose, $\mathrm{BUN}, \mathrm{Cr}$ 가 각 각 $2.4 \%, 4.7 \%, 4.7 \%, 8.2 \%, 2.5 \%$ 로 $10 \%$ 미만이었고 그 외 $\mathrm{Na}^{+}, \mathrm{Hct}, \mathrm{Hb}$ 는 각각 $36.5 \%, 24.7 \%, 20.0 \%$ 로 $10 \%$ 이상이 었다[11]. 또한 Bland-Altman 분석을 시행하여 측정한 편차 는 Fig. 3에 제시하였으며 그 중 $\mathrm{Na}^{+}$와 $\mathrm{TCO}_{2}$ 는 $\mathrm{i}-\mathrm{STAT}$ 에 의 한 측정값이 다소 높은 경향을 보여주었다 $(P<0.01)$.

\section{고찰}

본 연구에서는 i-STAT CHEM8+ 현장검사 장비의 정밀도 와 직선성, 그리고 대형검사 장비와의 상관성을 비교해보았고 그 결과 본 장비는 우수한 결과 값을 제공하는 것을 확인할 수 있었다. i-STAT은 $95 \mu \mathrm{L}$ 의 적은 혈액량을 필요로 하고, 검체

C

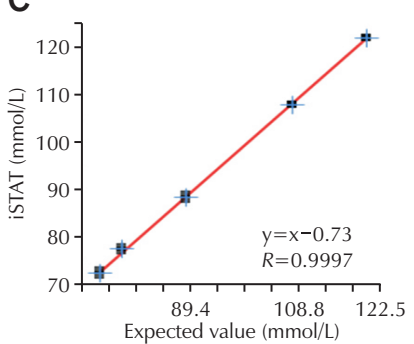

G

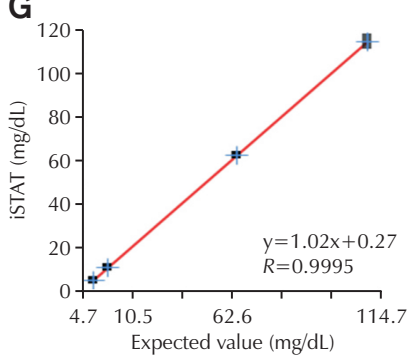

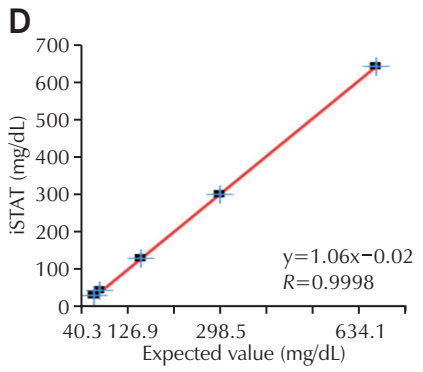

$\mathrm{H}$

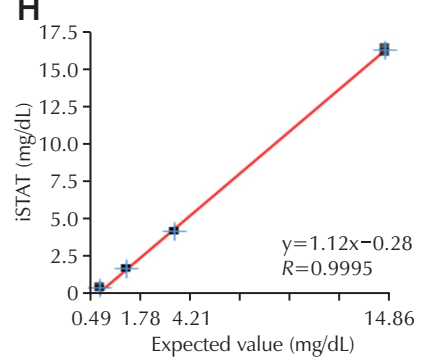

Fig. 1. The linearity of i-STAT CHEM8+. (A) $\mathrm{Na}^{+}$. (B) $\mathrm{K}^{+}$. (C) $\mathrm{Cl}^{-}$. (D) Ionised calcium. (E) Total $\mathrm{CO}_{2}$. (F) Glucose. (G) Blood urea nitrogen. (H) Creatinine. (I) Hematocrit. (J) Hemoglobin. 


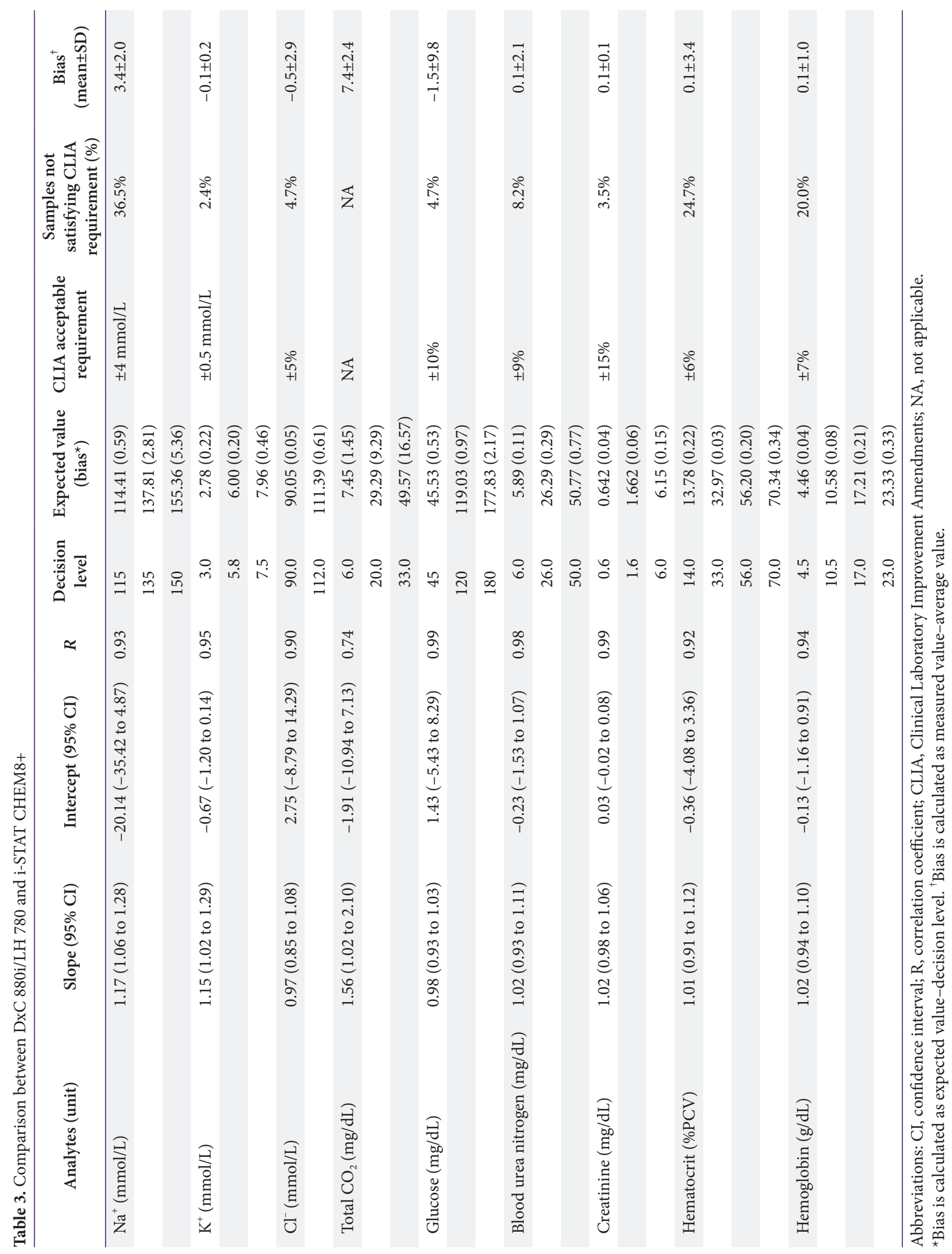


A

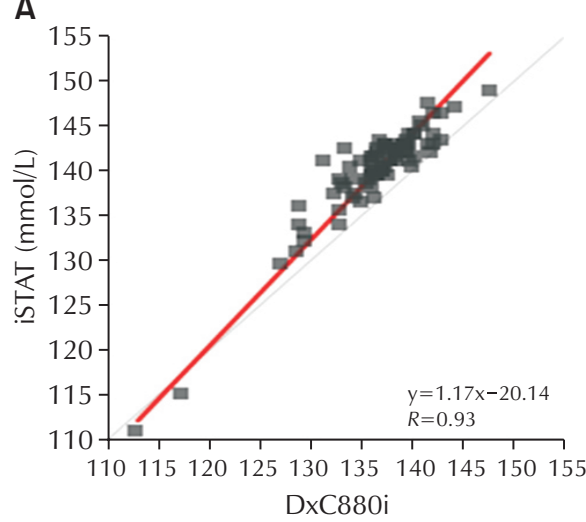

D

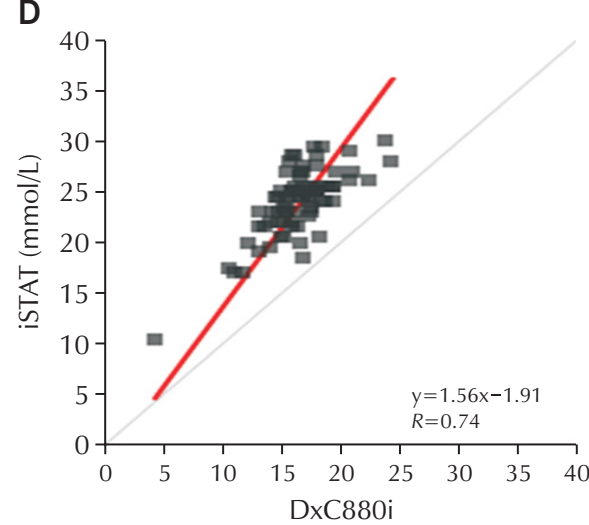

G

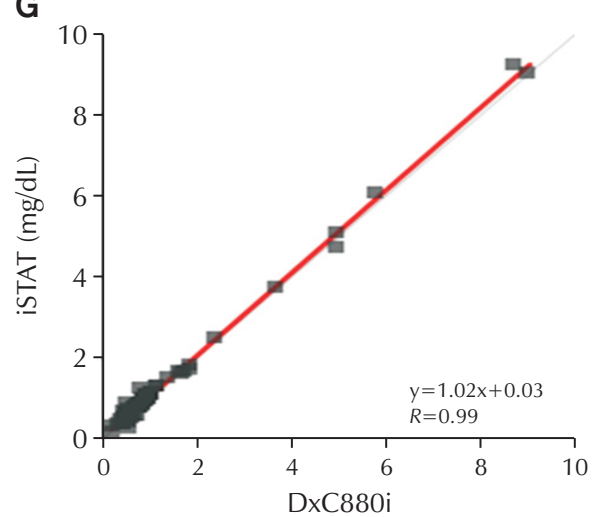

B

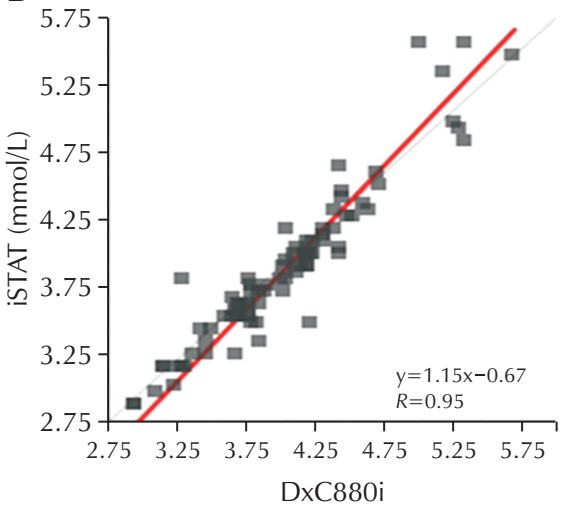

E

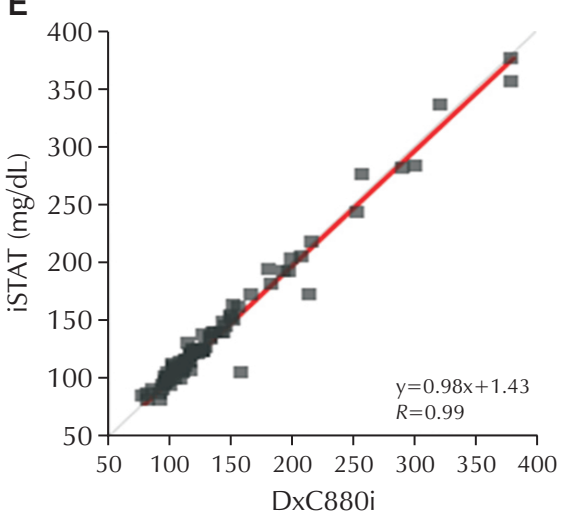

$\mathrm{H}$

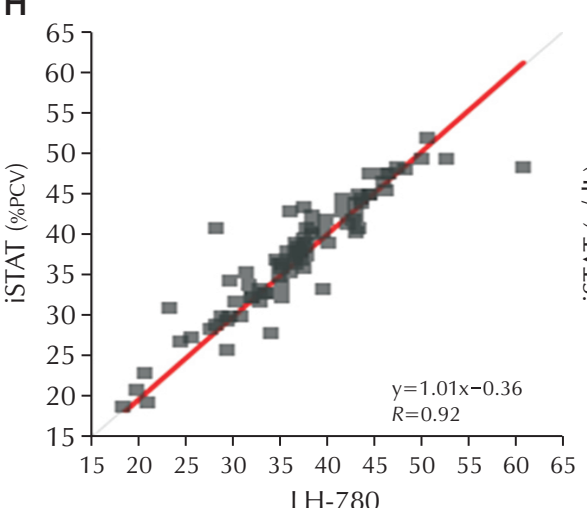

C

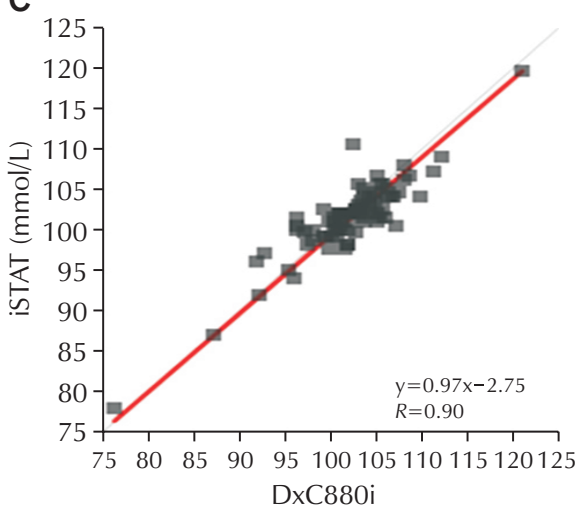

F

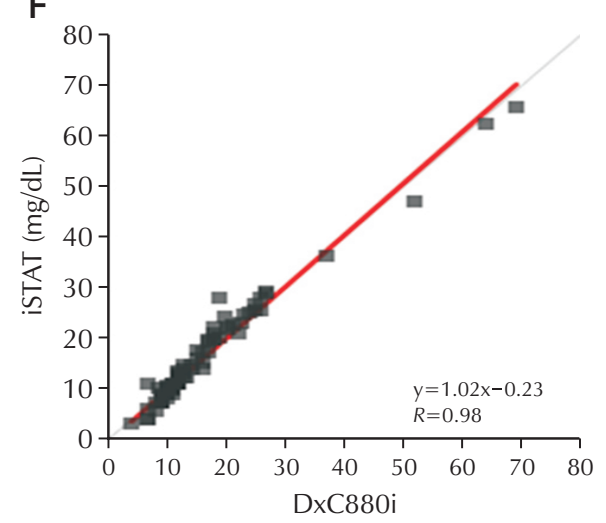

I

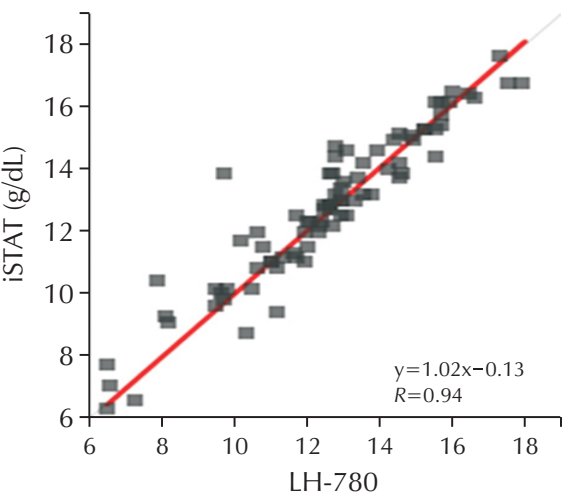

Fig. 2. Comparison between DxC 880i/LH 780 and i-STAT CHEM8+ measurements. (A) $\mathrm{Na}^{+}$. (B) $\mathrm{K}^{+}$. (C) $\mathrm{Cl}^{-}$. (D) Total $\mathrm{CO}_{2}$. (E) Glucose. (F) Blood urea nitrogen. (G) Creatinine. (H) Hematocrit. (I) Hemoglobin.

운송이나 원심분리와 같은 전처리과정의 부재로 신속하고 정 확한 검사결과를 제공하여 즉각적인 검사결과가 필요한 응급 실, 중환자실, 수술실, 혈액투석실 등에서 환자의 응급 정도를 구별하는 데 크게 기여할 수 있을 것으로 생각된다[2,3].

정밀도검사에서는 제조사에서 제공하는 저농도, 중간농도, 그리고 고농도의 정도관리물질을 각각 사용하여 $\mathrm{CHEM} 8+$ 에 해당하는 항목인 $\mathrm{Na}^{+}, \mathrm{K}^{+}, \mathrm{Cl}^{-}, \mathrm{TCO}_{2}, \mathrm{iCa}^{2+}$, glucose, $\mathrm{BUN}$, $\mathrm{Cr}, \mathrm{Hct}, \mathrm{Hb}$ 에 대하여 분석하였다. 측정한 10 가지 항목 중 저
농도 $\mathrm{Cr}$ 만 제외한 저농도, 중간농도와 고농도의 정도관리물질 모두 검사차례 내 및 총 변이계수가 $5 \%$ 미만으로 매우 우수한 것으로 확인되었다. 저농도 $\mathrm{Cr}$ 의 검사차례 내 및 총 변이계수 는 $7.3 \%$ 로 다소 높은 변이계수를 보였는데 이는 $7.7 \%$ 를 보였 던 기존의 평가와 비교하였을 때 비슷한 정도의 변이계수를 보 이는 것을 알 수 있었다[12]. 또한 임상적으로 문제가 되는 경 우는 대부분 고농도이고 응급실에서 조영제 사용 가능 여부 등 을 판단하기 위한 선별검사 목적으로 사용한다면 실제 사용하 
A

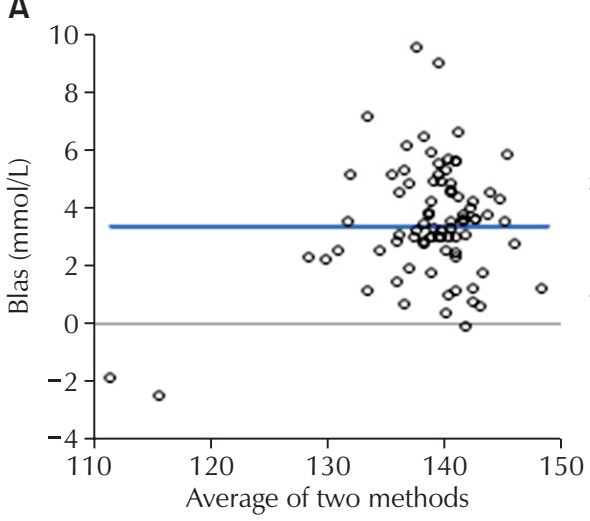

D

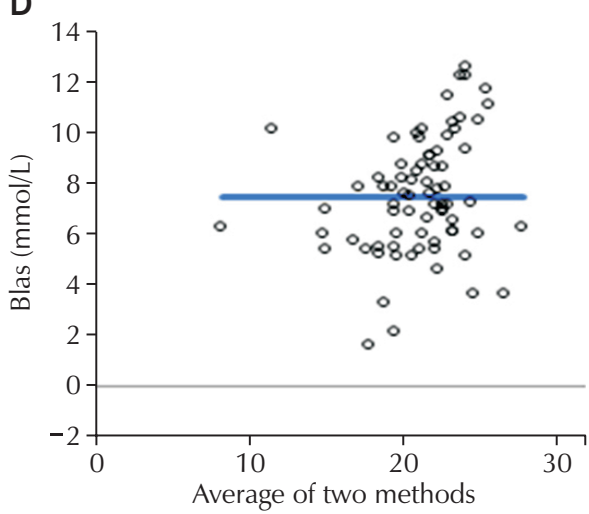

G

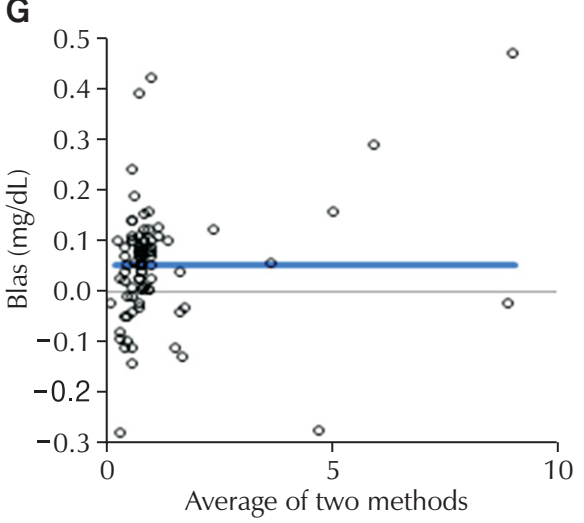

B

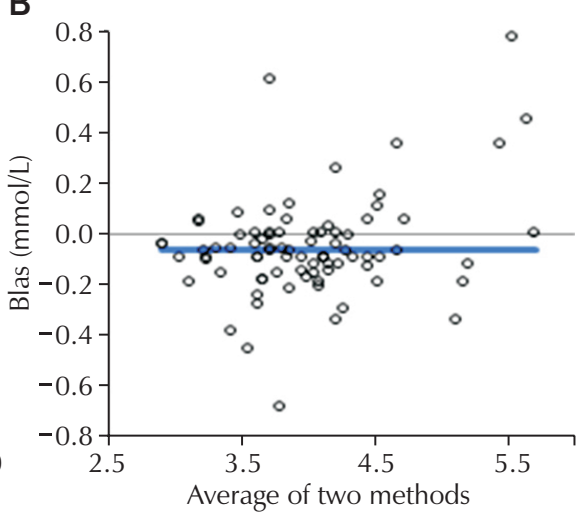

E

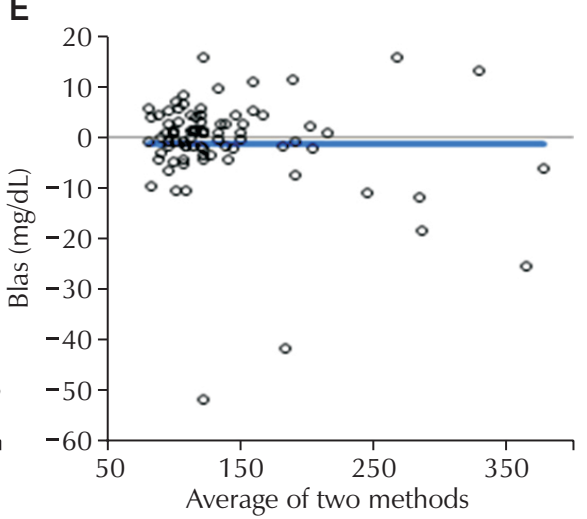

$\mathrm{H}$

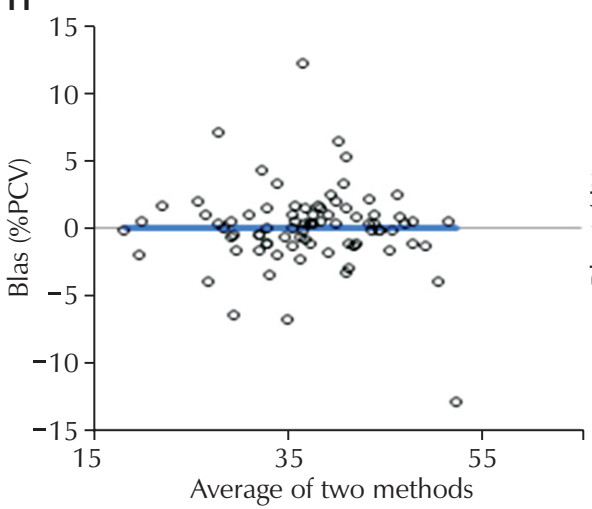

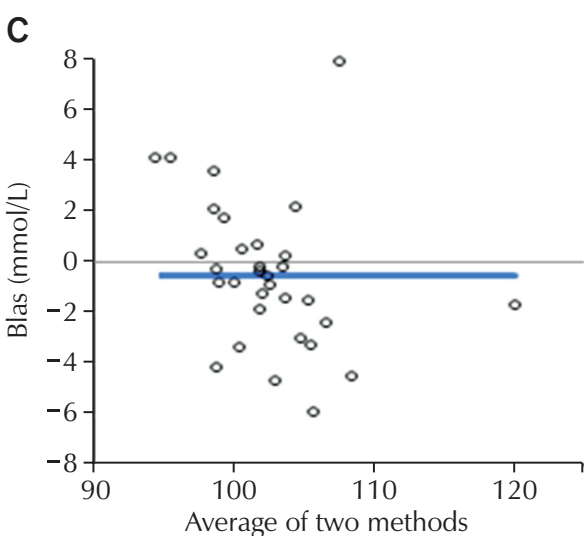

F

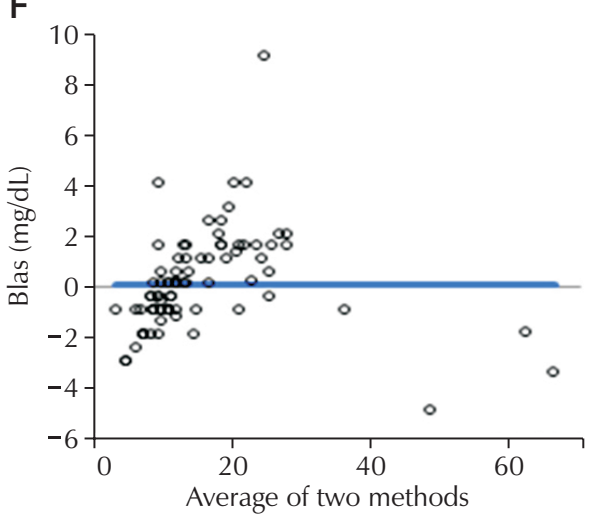

I

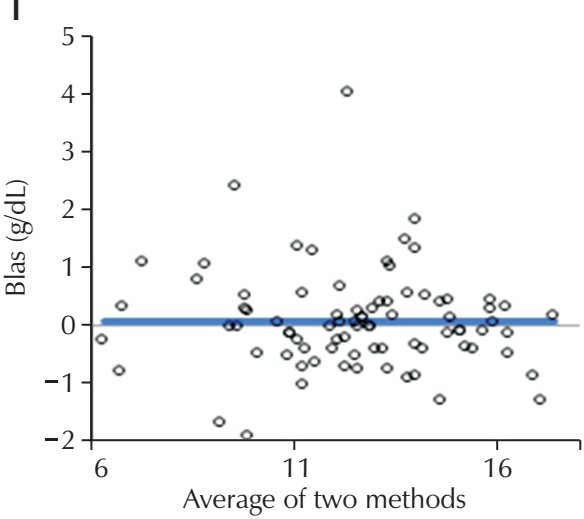

Fig. 3. Bland-Altman plots of the agreement between DxC 880i/LH 780 and i-STAT CHEM $8+$. The solid line indicates the mean bias. (A) $\mathrm{Na}^{+}$. (B) $\mathrm{K}^{+}$. (C) $\mathrm{Cl}^{-}$. (D) Total $\mathrm{CO}_{2}$. (E) Glucose. (F) Blood urea nitrogen. (G) Creatinine. (H) Hematocrit. (I) Hemoglobin.

기에는 큰 문제는 없을 것으로 생각된다[3].

직선성 검사에서는 제조사에서 제공하는 5 가지 농도의 정도 관리물질을 각각 사용하여 10 가지 항목에 대한 결정계수를 구 하였고 모두 0.975 이상으로 매우 우수한 결과를 보였다. 또한 각 측정치들과 목표치와의 차이는 모두 $10 \%$ 이내에 들었으며 직선성을 평가하는 데 사용한 5 가지 농도의 정도관리물질은 임상 검체에서 일반적으로 측정되는 값을 충분히 포함하여 임
상의들에게 정확한 정보를 제공할 수 있을 것으로 기대되었다. 상관성 평가에서는 i-STAT CHEM8+ 중 화학검사항목은 Beckman Unicel DxC 880i (Beckman Coulter Inc.)와, 혈 액검사항목은 Coulter LH 780 (Beckman Coulter Inc.)와 측 정한 결과값을 비교 · 분석한 결과 glucose, $\mathrm{BUN}, \mathrm{Cr}$ 은 상관 계수가 0.975 이상으로 매우 우수하였고 $\mathrm{Na}^{+}, \mathrm{K}^{+}, \mathrm{Hct}, \mathrm{Hb}$ 은 0.9 이상으로 우수한 상관성을 보였으며 $\mathrm{Cl}^{-}, \mathrm{TCO}_{2}$ 은 0.7 이상 
으로 양호한 상관성을 보였다[13]. $\mathrm{iCa}^{2+}$ 의 경우 채혈 2시간 이내에 본원 검사 장비에서 측정을 하지 못하여 상관성 분석을 시행하지 못하였다. 본 연구에서 $\mathrm{TCO}_{2}$ 의 상관계수는 0.738 로 다른 항목들에 비해 다소 낮게 나왔는데, 타연구에서 측정한 $\mathrm{TCO}_{2}$ 의 상관계수는 0.710 로 본 연구와 큰 차이를 보이지 않 았고 그 이유는 측정한 값의 범위가 비교적 좁기 때문일 것으 로 생각된다[3,12]. Deming 회귀분석을 통해 구한 방정식으 로 계산한 임상적 중요 농도 결과치의 경우 $\mathrm{Na}^{+}$고농도를 제 외한 나머지는 모두 CLIA에서 제시한 허용오차범위 내에 들 었다. 또한 CLIA에서 제시하는 허용오차범위를 만족하지 못 하는 검체의 비율은 $\mathrm{K}^{+}, \mathrm{Cl}^{-}$, glucose, $\mathrm{BUN}, \mathrm{Cr}$ 의 경우 $10 \%$ 미만이었으나 그 외 $\mathrm{Na}^{+}, \mathrm{Hct}, \mathrm{Hb}$ 는 $10 \%$ 이상으로 임상에 서 사용할 경우 환자의 임상양상을 고려한 판단이 필요할 것으 로 생각되었다[11]. Bland-Altman 분석에서 $\mathrm{Na}^{+}$와 $\mathrm{TCO}_{2}$ 는 i-STAT에 의한 측정값이 높은 경향을 보여 주었는데, 이는 이 전 연구결과와 큰 차이를 보이지 않으며, 그 원인으로 전혈과 혈청 등의 검체 종류 간의 차이, 검사실 온도, 기기 담당자, 검 사시간 등 여러 검사조건이 영향을 미쳤을 것으로 생각되었다 [5].

결론적으로, i-STAT CHEM8+는 정밀도, 직선성과 상관 성 평가에서 우수한 성능을 보였다. $95 \mu \mathrm{L}$ 의 적은 양의 전혈로 검체 채취 후 중앙검사실로의 운송뿐만 아니라 원심분리 등과 같은 검체 전처리과정이 없고 120 초 이내에 10 가지 항목에 대 하여 신속하고 정확한 검사결과를 확인할 수 있으며 조작이 간 편하기 때문에 즉각적인 검사결과가 필요한 응급실, 중환자실, 수술실, 혈액투석실 등에서 유용하게 사용될 수 있을 것으로 기대된다[12].

\section{REFERENCES}

1. Clinical and Laboratory Standards Institute. Selection criteria for point-of care testing devices: approved guideline. Wayne (PA): Clinical and Laboratory Standards Institute, 2010.

2. Jeong TD, Kang HJ, Kim MS, Kim SY, Lee W, Chun S, et al. Evaluation of the performance of LABGEO PT Hepatic Test 9. Lab Med Online 2013;3:138-44.
3. Park H, Ko DH, Kim JQ, Song SH. Performance evaluation of the Piccolo xpress Point-of-care Chemistry Analyzer. Korean J Lab Med 2009;29:430-8.

4. Dascombe BJ, Reaburn PR, Sirotic AC, Coutts AJ. The reliability of the i-STAT clinical portable analyser. J Sci Med Sport 2007;10:135-40.

5. Yi SG, Lee SY, Kim JW. Evaluation of the i-STAT pointof-care testing analyzer. Korean J Lab Med 2002;22:30411.

6. Nichols JH. Point of care testing. Clin Lab Med 2007;27: 893-908.

7. Clinical and Laboratory Standards Institute. User verification of performance for precision and trueness: approved guideline. 2nd ed. Wayne (PA): Clinical and Laboratory Standards Institute, 2005.

8. Clinical and Laboratory Standards Institute. Evaluation of the linearity of quantitative measurement procedures: a statistical approach: approved guideline. Wayne (PA): Clinical and Laboratory Standards Institute, 2003.

9. Clinical and Laboratory Standards Institute. Method comparison and bias estimation using patient samples: approved guideline. 2nd ed. Wayne (PA): Clinical and Laboratory Standards Institute, 2002.

10. Statland BE. Clinical decision levels for laboratory tests. 2nd ed. Oradell (NJ): Medical Economics Books, 1987.

11. Centers for Disease Control and Prevention. Clinical Laboratory Improvement Amendments regulation: standards and certification: laboratory requirements. http://wwwn.cdc.gov/clia/Regulatory/default.aspx (Accessed March 21, 2016).

12. Kim DK, Shin H, Kim B, Jeong SH, Lim JB. Evaluation of i-STAT CHEM8+ Point-of-care Chemistry Analyzer. Lab Med Online 2015;5:57-62.

13. Zady RM. Z-STATS 12: correlation and simple least squares regression. https://www.westgard.com/lesson 42. htm (Assessed March 21, 2016). 


\section{현장검사장비 i-STAT의 성능평가}

\section{오예진 • 구선회 • 권계철}

충남대학교 의과대학 충남대학교병원 진단검사의학과

배경: 현장검사란 중앙검사실을 벗어나 진료가 이루어지는 장소에서 시행되는 진단검사로 최근 그 수 요가 증가하고 있으며 이로 인해 빠른 진단 및 치료가 가능해지고 있다. 본 연구에서는 현장검사 장비 인 i-STAT (Abbott Diagnostics, USA)을 이용하여 혈중 8가지 화학항목인 $\mathrm{Na}^{+}, \mathrm{K}^{+}, \mathrm{Cl}^{-}$, total $\mathrm{CO}_{2}$ $\left(\mathrm{TCO}_{2}\right)$, ionised calcium, glucose, blood urea nitrogen (BUN), creatinine (Cr)과 2가지 혈액 항 목인 (hematocrit [HCT], hemoglobin [Hb]) 농도를 측정하여 그 수행능을 평가하였다.

방법: 정밀도 평가는 Clinical and Laboratory Standards Institute (CLSI) EP15-A3, 직선성 평가

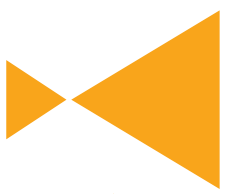

Journal of

LABORATORY MEDICINE and

QUALITY ASSURANCE 는 CLSI EP6-A에 따라 평가하였다. 상관성 평가는 CSLI EP9-A3에 따라 임상 검체 85개를 이용 하여 Coulter LH 780 (Beckman Coulter Inc., USA)와 Beckman Unicel DxC 880i (Beckman Coulter Inc.)를 이용하여 i-STAT과 비교분석하였다.

결과: 정밀도 평가에서는 측정한 10 가지 항목 중 저농도 $\mathrm{Cr}$ 만 제외하고 저농도, 중간농도와 고농도의 정도관리물질 모두 검사차례 내 및 총 변이계수가 $5 \%$ 미만이었다. 직선성 평가에서의 결정계수는 평 가항목 모두 0.975 이상이었다. 상관성 평가에서는 glucose, BUN, Cr은 상관계수가 0.975 이상으 로 매우 우수하였고 $\mathrm{Na}^{+}, \mathrm{K}^{+}, \mathrm{Hct}, \mathrm{Hb}$ 은 0.9 이상으로 우수한 상관성을 보였으며 $\mathrm{Cl}^{-}, \mathrm{TCO}_{2}$ 은 0.7 이상으로 양호한 상관성을 보였다.

결론: 결론적으로, i-STAT을 정밀도, 직선성과 상관성 평가에서 우수한 성능을 보였다. 때문에 즉각 적인 검사결과가 필요한 부서에서 유용하게 사용될 수 있을 것으로 기대된다.

(J Lab Med Qual Assur 2016;38:225-233) 